\title{
Robust MRAC-based adaptive control of a Doubly Fed Induction Generator (DFIG) in a Wind energy system using a fractional order Integrator
}

\author{
Sihem Djebbri ${ }^{(1)}$, Hanane Balaska ${ }^{(2)}$, Samir Ladaci ${ }^{(3,4)}$, \\ ${ }^{(1)}$ Electrical Engineering Department, University of $20^{\text {th }}$ August 1955, Skikda, 21000 Algeria. \\ Email: s.djebbri@yahoo.fr \\ (2) Department of Science and Technology, University Larbi Ben M'Hidi, Oum El-Bouaghi, 04000 Algeria. \\ ${ }^{(3)}$ E.E.A. Department, National Polytechnic School of Constantine, Constantine, 25100 Algeria \\ ${ }^{(4)}$ SP-LAB Laboratory, Depart. Electronics, UMC1 University, Constantine, 25000 Algeria.
}

Email: samir_ladaci@yahoo.fr

\begin{abstract}
This paper presents a robust control of doubly fed induction generator for wind generation system. The whole system is presented in $d$-q-synchronous reference frame. We propose the implementation of adaptive control with integer model reference MRAC, fractional model reference FOMRAC with integer and fractional order control law design for active and reactive power supervision control in the doubly fed induction generator (DFIG) for wind energy systems.

The objective is to realize a comparative study between the classical regulator MRAC and the proposed FOMRAC with integer and fractional order control law in order to demonstrate the robustness of the fractional order adaptive control with fractional order integral in control law comparatively to integer order one. Performance and robustness results obtained will be presented and analyzed.
\end{abstract}

Keywords: Doubly fed induction generator (DFIG); Renewable energy; MRAC; FOMRAC; Robustness

\section{INTRODUCTION}

Currently, the wind using a doubly-fed induction generator "DFIG» are the more used for production of the electric energy [1, 4]. Nowadays, wind generation system based on a doubly fed induction generator (DFIG) are employed widely in large wind farms fat has its many advantages: a very good energy efficiency, robust sensorless operation $[5,6]$. In addition, the power converter is usually rated at $25-30 \%$ of the generator power rating [7-10], For such several advantages, this machine has generated a lot of curiosity on the part of researchers have tried to develop strategies to best exploit its strong points [11].

The problematic studied in this paper is to find a type of control independent to the parametric variations of the machine, that is realized by adaptive control with integer order model reference MRAC and fractional order model reference FOMRAC.

Beginning with the earlier works of Vinagre at al [12] and Ladaci et al $[13,15]$, fractionalorder model reference adaptive control (FO-
MRAC) has gathered a great interest from the community of control engineering researchers. This popularity is mainly due to its simple principle and easiness to implement on one hand and its improved performance and robustness comparatively to classical adaptive control schemes on the other [16].

Many application of fractional-order model reference adaptive control schemes are also available in literature in different science and engineering fields like: in Electric Vehicle Using a fractional order model reference adaptive strategy[17], Voltage control of $\mathrm{DC} / \mathrm{DC}$ converter in multi sources renewable [18], and a multi-source renewable energy system using fractional-Order Integrals [19]...etc.

Finally, a comparative study is carried on using the quadratic error criterion, calculating this last for integer MRAC and fractional order model reference FOMRAC in each case for active and reactive powers.

The paper is organized as follows. Section 2 , describes the modeling studied system 
with the control of active and reactive power. Then fractional order MRAC control theory will be presented in section 3 . The results of simulations obtained are presented and discussed for validating the proposed controller in Section 4. We propose a robustness test with parameters fluctuation by rotor resistance change in section 5 . Finally, the conclusion is drawn in section 6.

\section{DFIG SYSTEM MODELLING}

When modeling a doubly fed induction machine, it is essential to consider that this kind of wound rotor machine has to be fed both from stator and rotor sides, as sketched in Fig.1. normally, the stator is directly connected to the grid and the rotor is interfaced through a variable frequency power converter. In order to cover a wide operation range from subsynchronous to synchronous speeds, the power converter placed on the rotor side bas to able to operate with power flowing in both directions [4].

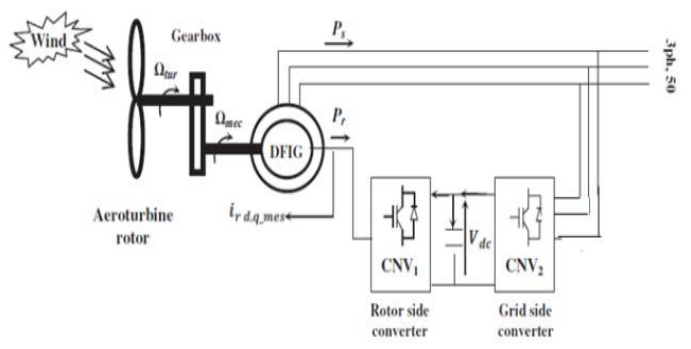

Fig. 1 Doubly fed induction machine basic configuration for wind turbine.

The mathematical model can be expressed as [5]:

The stator voltage equation:

$$
\left\{\begin{array}{l}
V_{s q}=R_{s} I_{s q}+\frac{d}{d t}\left(\phi_{s q}\right)+\omega_{s} \phi_{s d} \\
V_{s d}=R_{s} I_{s d}+\frac{d}{d t}\left(\phi_{s d}\right)-\omega_{s} \phi_{s q}
\end{array}\right.
$$

The rotor voltage equation:

$$
\left\{\begin{array}{l}
V_{r d}=R_{r} I_{r d}+\frac{d}{d t}\left(\phi_{r d}\right)-\left(\omega_{s}-\omega_{r}\right) \phi_{r q} \\
V_{r q}=R_{r} I_{r q}+\frac{d}{d t}\left(\phi_{r q}\right)+\left(\omega_{s}-\omega_{r}\right) \phi_{r d}
\end{array}\right.
$$

The stator flux linkage equation:

$$
\left\{\begin{array}{l}
\phi_{s d}=L_{s} I_{s d}+M I_{r d} \\
\phi_{s q}=L_{s} I_{s q}+M I_{r q}
\end{array}\right.
$$

The rotor flux linkage equation:

$\left\{\begin{array}{l}\phi_{r d}=L_{r} I_{r d}+M I_{s d} \\ \phi_{r q}=L_{r} I_{r q}+M I_{s q}\end{array}\right.$

Electromagnetic torque equation:

$J \frac{d \Omega}{d t}=\left(\frac{J}{p} \frac{d \omega_{r}}{d t}\right)=-\frac{3}{2} p \frac{M}{L_{s}}\left(\phi_{r d} I_{s q}-\phi_{r d} I_{s d}\right)-C_{r}-f_{r} \Omega$

\subsection{Reference frame}

By choosing a reference frame linked to the stator flux, rotor currents will be related directly to the stator active and reactive power. If the stator flux is linked to the $d$-axis of the frame we have [8]:

$$
\psi_{d s}=\psi_{s} \text { and } \psi_{q s}=0
$$

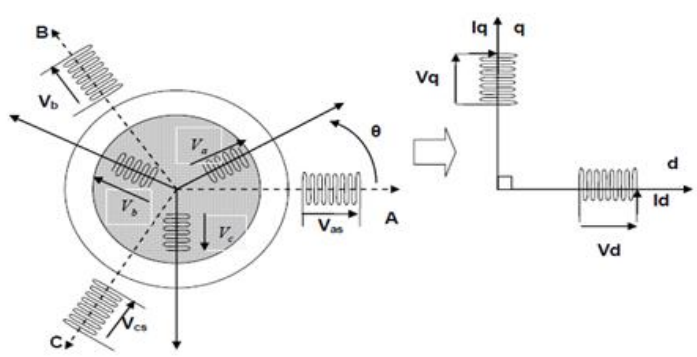

Fig. 2 PARK's model of DFIG.

\subsection{Control strategy}

The torque and consequently the active power only depend on the $q$-axis rotor current component. If the per phase stator resistance is neglected, the stator voltage vector is in quadrature advance in comparison with the stator flux vector [9].

$$
V_{d s}=0 \text { and } V_{q s}=V_{s}=\omega_{s} \psi_{s}
$$

The stator active and reactive power can then be expressed only versus these rotor currents as:

$$
\begin{aligned}
& \left\{\begin{array}{l}
P=-V_{s} \frac{M}{L_{s}} i_{q r} \\
Q=\frac{V_{s} \phi_{s}}{L_{s}}-\frac{V_{s} M}{L_{s}} i_{d r}
\end{array}\right. \\
& \left\{\begin{array}{l}
V_{r d}=R_{r} I_{r d}+\left(L_{r}-\frac{M^{2}}{L_{s}}\right) \frac{d i_{d r}}{d t}-g \omega_{s}\left(L_{r}-\frac{M^{2}}{L_{s}}\right) i_{q r} \\
V_{r q}=R_{r} I_{r q}+\left(L_{r}-\frac{M^{2}}{L_{s}}\right) \frac{d i_{q r}}{d t}+g \omega_{s}\left(L_{r}-\frac{M^{2}}{L_{s}}\right) i_{q r}+g \omega_{s} \frac{M V_{s}}{\omega_{s} L_{s}}
\end{array}\right.
\end{aligned}
$$

The inputs block relating $V_{d q}$ to $V_{d q r}$ present a simplified rotor converter model.

\section{FRACTIONAL ORDER MRAC CONTROL}

Adaptive control is the control method used by a controller which must adapt to a 
controlled system with parameters which vary, or are initially uncertain.

\subsection{Linear approximation of fractional order Transfer function}

In order to approximate the fractional order model reference we use the so-called singularity function method proposed by Charef (see [13-14]). For fractional second order system with $\mathrm{m}$ a positive real number such that $0<m<1$,

$$
H(s)=\frac{1}{\left(\frac{s^{2}}{\omega^{2}}+2 \xi \frac{s}{\omega}+1\right)^{m}}
$$

Can be expressed as:

$$
H(s)=\frac{\left(\frac{s}{\omega}+1\right)\left(\frac{s}{\omega+1}\right)^{\beta}}{\left(\frac{s^{2}}{\omega^{2}}+2 \alpha \frac{s}{\omega}+1\right)}
$$

with $\alpha=\xi^{m}$ and $\beta=1-2 m$, which can also be approximated by the function (19):

$$
H(s)=\frac{\left(\frac{s}{\omega}+1\right)}{\left(\frac{s^{2}}{\omega^{2}}+2 \alpha \frac{s}{\omega}+1\right)} \frac{\prod_{i=1}^{N-1}\left(1+\frac{s}{z_{i}}\right)}{\prod_{i=1}^{N}\left(1+\frac{s}{p_{i}}\right)}
$$

\subsection{Model Reference Adaptive Control}

The controller parameter adjustment is achieved by mean of the error between the output of the plant and the model reference output. This can be represented in fig. 3 .

The control signal is computed using the following relation,

$$
u=\varphi^{T} . \theta
$$

Where $\varphi$ is the regression vector containing the measured input signals $u$ and output signals $y$ and the input reference signal $u_{c}$.

\subsection{M.I.T. Rule:}

We consider a closed loop system where the controller has an adjustable parameter vector $\theta$. A model which output is $y_{m}$ specifies the desired closed loop response. Let $\mathbf{e}$ be the error between the closed loop system output $\mathbf{y}$ and the model one $y_{m}$, one possibility is to adjust the parameters such that the cost function:

$$
\mathrm{J}(\theta)=\frac{1}{2} \mathrm{e}^{2}
$$

Be minimized. In order to make $\mathbf{J}$ small it is reasonable to change parameters in the direction of negative gradient $\mathbf{J}$, so:

$$
\frac{\mathrm{d} \theta}{\mathrm{dt}}=-\gamma \frac{\partial \mathrm{J}}{\partial \theta}=-\gamma \mathrm{e} \frac{\partial \mathrm{e}}{\partial \theta}
$$

Wish leads to the following blocs scheme of fig.3,

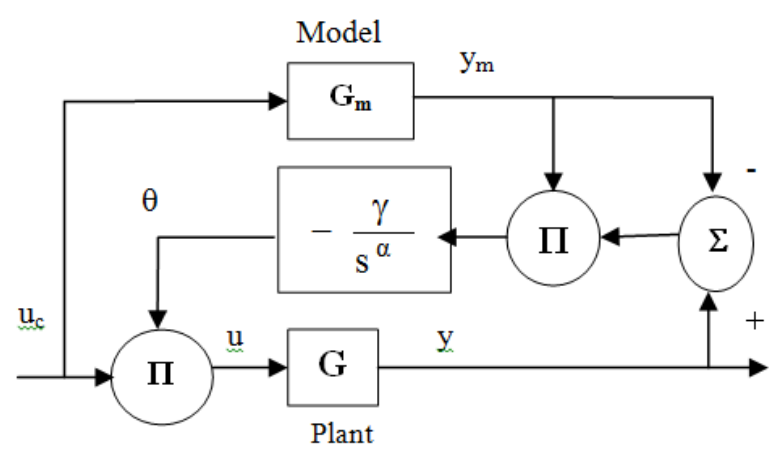

Fig. 3Adaptation algorithm

\subsection{Introducing Fractional Integration:}

Let $\alpha \in C, \mathfrak{R}(\alpha)>0, \quad \mathrm{c} \in \mathrm{R}$ and $\mathrm{f}$ a locally integrable function defined on $[\mathrm{c},+\infty[$. The $\alpha$ order integral of $f$, of lower bound $\mathrm{c}$ is defined as [12-23]:

$$
I_{c}^{\alpha} f(t) \stackrel{\Delta}{=} \int_{c}^{t} \frac{(t-\tau)^{\alpha-1}}{\Gamma(\alpha)} f(\tau) d \tau
$$

With $\mathrm{t} \geq \mathrm{c}$, and $\Gamma$ is the Euler function. The formula (18) is called Riemann-Liouville Integral.

Usually, the control loop is discreet, and we use a sampled approximation of (18) given by:

$$
I_{c}^{\alpha} f(k \Delta)=\frac{\Delta}{\Gamma(\alpha)} \sum_{\tau=0}^{k-1}(k \Delta-\tau \Delta)^{\alpha-1} f(\tau \Delta)
$$

With, $\Delta$ : Sampling Period.

In the adjusting algorithm represented by the bloc-scheme of figure.4, we put an order integration with $\alpha$ non-zero positive real such that: $0<\boldsymbol{\alpha}<2$. We get then:

$$
\theta=-\frac{\gamma}{s^{\alpha}} y_{m}\left(y-y_{m}\right)=-\frac{\gamma}{s^{\alpha}} y_{m} e
$$

3.5 Application of Model Reference adaptive control to DFIG active and reactive power control in wind energy conversion

The block diagram of the MRAC control of active and reactive power of DFIG is shown in fig. 4, by adding the parameters of the DFIG system presented in table 1. 


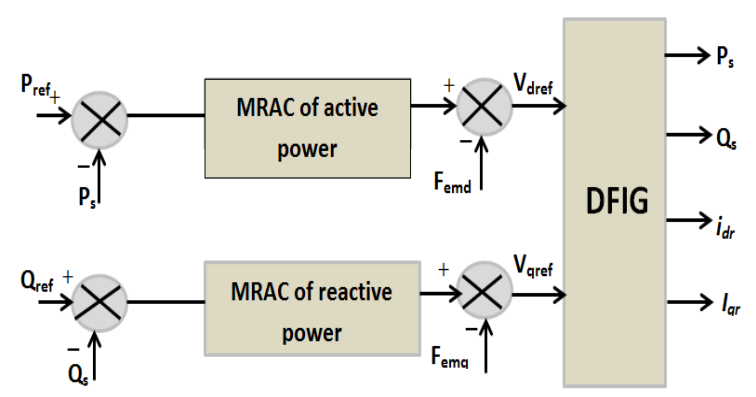

Fig. 4 Model reference adaptive control MRAC of active and reactive power of DFIG in wind system

Table 1 Characteristic parameters of the DFIG

$\begin{array}{cc}\text { Parameter } & \text { Value } \\ V_{\text {seff }} & 230 \mathrm{~V} \\ p & 2 \text { pairs of poles. } \\ R_{s} & 0.455 \Omega \\ R_{r} & 0.19 \Omega \\ L_{s} & 0.07 \mathrm{H} \\ L_{r} & 0.0213 \mathrm{H} \\ M_{s r} & 0.034 \mathrm{H} \\ f & 50 \mathrm{~Hz}\end{array}$

\section{RESULTS AND INTERPRETATION}

In this section, we will have the results of simulation of the uncoupled control from the active and reactive powers generated doubly fed induction generator DFIG of the wind energy, using fractional order FOMRAC, whose objective is to compare the responses powers active and reactive compared to the references desire.

\subsection{MRAC controller}

The system is described using the following equation:

$$
\mathrm{H}(\mathrm{S})=\frac{M \cdot V_{s}}{L_{s} \cdot R_{r}+S \cdot L_{s}\left(L_{r}-\frac{M^{2}}{L_{s}}\right)}
$$

The numerical replacement gives the following transfer function:

$$
\mathrm{H}(\mathrm{S})=\frac{Y(s)}{U(S)}=\frac{2.334 e 04}{S+39.7}=\frac{B}{A}
$$

According to the characteristics of the system studies, the reference model is chosen as:

$$
\mathrm{G}_{\mathrm{M}}(\mathrm{S})=\frac{6.4 .10^{7}}{\left(S^{2}+15200 S+6.4 .10^{7}\right)^{m}}
$$

The RST control structure is characterized by the Diophantine equation:
$A \cdot R+B . S=A_{r}=A_{0} \cdot A_{m}$

Where $R, S$ and $T$ are polynomials and $A_{o}$ is a stable polynomial called the "observer" polynomial.

Therefore, the regulation parameters vector is given as:

$$
\theta=\left[\begin{array}{lllll}
r_{0} & s_{0} & s_{1} & t_{0} & t_{1}
\end{array}\right]
$$

and the regression vector,

$$
\varphi^{T}=\frac{b_{0}}{A_{0} A_{m}}\left[\begin{array}{lllll}
U & \text { Sy } & y & -S u c & -u c
\end{array}\right]
$$

s : Laplace operator.

The recurrence equation of $\varphi^{T}$ obtained after the discretization ( $T=0.001 \mathrm{~s}$ ) is given by :

phi $(\mathrm{t}+1,:)=-0.0008007 *$ phi $(\mathrm{t},:)-2.505 \mathrm{e}-07 *$ phi $(\mathrm{t}-$ $1,:)+a l p h a(t,:)$

\subsection{FOMRAC controllers}

The reference model is a fractional order system of second order-like of the from (10) with $\mathrm{m}=0,4$. Using Charef's approximation method we obtain the approximating rational transfer function given by:

$$
G_{m}(S)=\frac{6 \cdot 4 \cdot 10^{07}}{\left(S^{2}+15200 . S+6.4 \cdot 10^{07}\right)^{0.4}}
$$

The approximation function is of order 5 :

$$
G_{a p}^{0.4}(S)=\frac{7.308 \cdot 10^{-09} \cdot \mathrm{S}^{2}+0.0001806 \mathrm{~S}+1}{6.376 .10^{-22} \mathrm{~S}^{5}+7.412 .10^{-17} \mathrm{~S}^{4}+2.909 .10^{-12} \mathrm{~S}^{3}+4.893 .10^{-8} \mathrm{~S}^{2}+0.0003641 \mathrm{~S}+1}
$$

Then $\operatorname{deg}\left(A_{m}\right)=5$ and from the Diophantine equation (22) we obtain: $\operatorname{deg}(S)=\operatorname{deg}(R)=$ $\operatorname{deg}(S)=4$.

Therefore, the regulation parameters vector is given as:

$\theta=\left[\begin{array}{llllllllllllll}r_{1} & r_{2} & r_{3} & r_{0} & s_{0} & s_{1} & s_{2} & s_{3} & s_{4} & t_{0} & t_{1} & t_{2} & t_{3} & t_{4}\end{array}\right]$

and the regression vector,

$\varphi^{t}=\frac{b_{0}}{A_{0} A_{m}}\left[\begin{array}{ccc}s^{k-1} u \ldots . u & s^{l} y \ldots . y & -s^{m} u_{c} \ldots . . u_{c}\end{array}\right]$

Fig. 5 and 6 show comparative results for active and reactive power control respectively using integer and fractional order MRAC. 


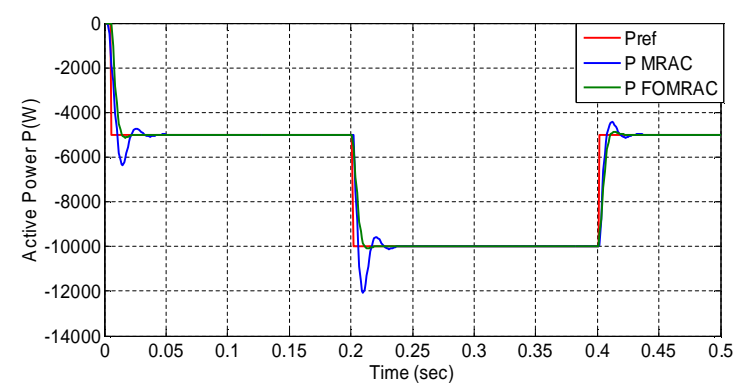

Fig. 5 Active power output comparison between integer reference model (blue) and Fractional order reference models (green) with $\mathrm{m}=0.4$

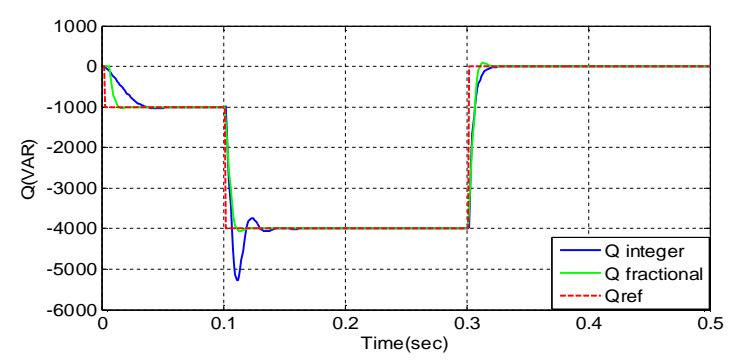

Fig. 6 Reactive power output comparison between integer reference model (blue) and Fractional order reference model (green) with $\mathrm{m}=0.4$

4.3 FOMRAC with random output noise Let us consider the proposed FOMRAC controller for $m=0,4$ in presence of random output noises of $30 \%$ of the reference signal amplitude. The simulation results are given in Fig. 7 for active power and Fig. 8 for reactive power respectively.

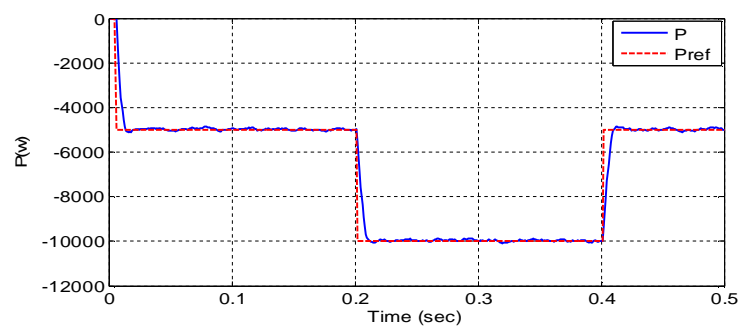

Fig. 7 Active power with FO-MRAC with random output noise of $30 \%$ of the reference signal amplitude.

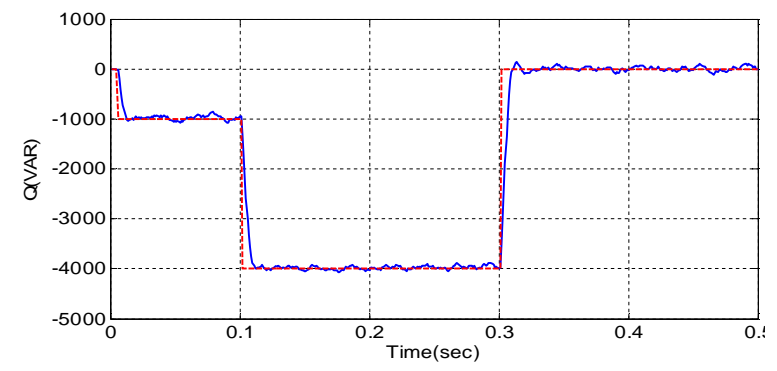

Fig. 8 Reactive power with FO-MRAC with random output noise of $30 \%$ of the reference signal amplitude.
And let us define the quadratic cost function criteria for the tracking error Je and the input energy Ju as follows,

$$
\begin{aligned}
& J_{e}=\sqrt{\sum_{n=0}^{N_{\max }}\left(u_{c}(n)-y(n)\right)^{2}} \\
& J_{u}=\sqrt{\sum_{n=0}^{N_{\max }} u(n)^{2}}
\end{aligned}
$$

Computing these criteria for different values of the fractional order $\mathrm{m}$ and the integer case, we obtain,

Table $2 \mathrm{~J}_{\mathrm{e}}$ and $\mathrm{J}_{\mathrm{u}}$ criteria for active power with FOMRAC $(m=0.4,0.7,0.9,1)$.

$\begin{array}{ccc}M & \mathrm{Je}(\mathrm{P}) & \mathrm{Ju}(\mathrm{P}) \\ 0.4 & \mathbf{1 4 6 6 7 . 7} & 312.66 \\ 0.7 & 16109.7 & \mathbf{3 0 9 . 1 9} \\ 0.9 & 25115.1 & 349.02 \\ 1 & 16088.0 & 337.80\end{array}$

Table $3 J_{e}$ and $J_{u}$ criteria for reactive power with fractional order reference models FO-MRAC $(\mathrm{m}=$

$\begin{array}{ccc} & 0.4,0.7,0.9,1) . & \\ M & \mathrm{Je}(\mathrm{Q}) & \mathrm{Ju}(\mathrm{Q}) \\ 0.4 & \mathbf{8 9 9 5 . 1} & 122.58 \\ 0.7 & 10054.3 & \mathbf{1 2 0 . 1 4} \\ 0.9 & 11895.9 & 135.48 \\ 1 & 10044.8 & 135.67\end{array}$

\subsection{Fractional order integration}

The reference model is a fractional order system of second order-like of the from (10) with $\mathrm{m}=0,4$. Using fractional order integration (17) with $\alpha$ the fractional order of integral (control law), we obtain,

Table 4. Quadratic error criteria $J_{e}$ with different approaches of adaptive control of active power

$\begin{array}{lll}\text { MRAC } & & \begin{array}{c}J_{e} \text { for } P(w) \\ 16088.027\end{array} \\ \text { FOMRAC } & m=1 & 14667.699 \\ \text { FOMRAC with } & m=0.4 & 14657.843 \\ \text { integration } & \alpha=1.2 & \\ & & \\ \text { FOMRAC with } & m=0.4 & 14666.596 \\ \text { integ + random } & \begin{array}{l}\alpha=1.2 \\ \text { Random15\% }\end{array} & \\ & \end{array}$

Table 5 Quadratic error criteria $J_{e}$ with different approaches of adaptive control of reactive power

$\begin{array}{llc}\text { MRAC } & \mathrm{m}=1 & \mathrm{~J}_{\mathrm{e}} \text { for } \mathrm{Q}(\mathrm{VAR}) \\ \text { FOMRAC } & \mathrm{m}=0.4 & 89044.879 \\ & \mathrm{a}=0.4 & \\ \text { FOMRAC } & \mathrm{m}=0.4 & 8985.089 \\ \text { With integration } & \mathrm{\alpha}=1.2 & \\ \begin{array}{l}\text { FOMRAC } \\ \text { With integ. + }\end{array} & \mathrm{m}=0.4- & 9006.728 \\ \text { random } & \mathrm{a}=1.2 & \\ & \text { Random } 15 \% & \end{array}$




\section{PARAMETRIC ROBUSTNESS TEST}

The test consists in varying the parameters of the model of GADA used (test of robustness) with the maintenance of the conditions of the first test. We suppose that the rotor resistance of the doubly fed induction generator DFIG increases by $+25 \%$ and $50 \%$ between $t=[0.25-0.27] \mathrm{s}$, as represented in Table 6.

Table 6. System TF with Rotor resistance variation.

$\begin{array}{cc}\begin{array}{c}\text { Rr increase } \\ 0 \%\end{array} & \mathrm{G}\{\mathrm{P}, \mathrm{Q}\}(\mathrm{s}) \\ 25 \% & \frac{23340}{s+39.7} \\ & \frac{23340}{s+45.63} \\ 50 \% & \frac{23340}{s+59.55}\end{array}$

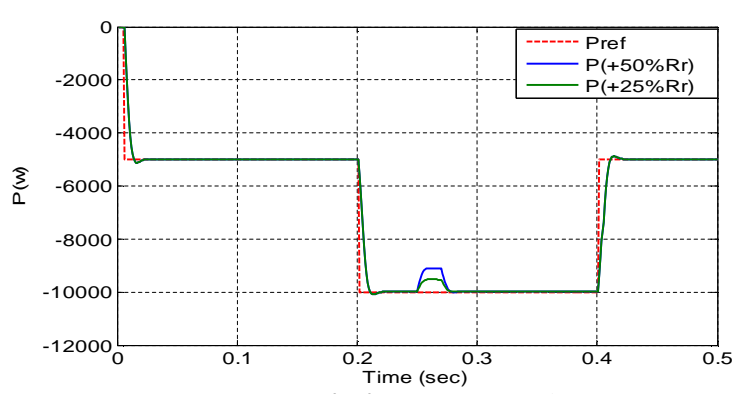

Fig.9 Active power $\mathrm{P}(\mathrm{W})$ output with fractional reference model FO-MRAC with different increases in rotor resistance $\mathrm{R}_{\mathrm{r}}(+25 \%$ and $+50 \%)$.

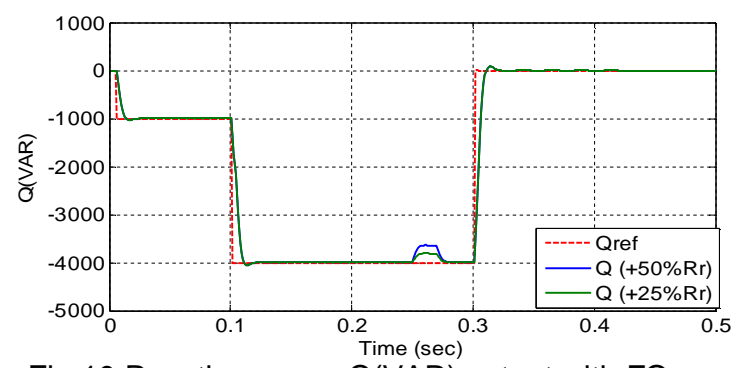

Fig.10 Reactive power $\mathrm{Q}(\mathrm{VAR})$ output with FOMRAC with different $R_{r}(+25 \%$ and $+50 \%)$.

Whereas fig. 5 and 6 prove that the FOMRAC control with fractional order reference gives better performance than the integer order MRAC because the responses of active and reactive power follow perfectly the suggested references, besides, Tables 2 and 3 which confirm that the tracking error obtained for FO-MRAC $(m=0.4)$ is smaller than that obtained for the MRAC for active and reactive power control.

\section{CONCLUSIONS}

In this paper, fractional Model reference adaptive control algorithm (FOMRAC) which includes the use of fractional integral was presented that can guarantee the stability with a satisfying level of performances.

First, a fractional order model reference adaptive control (FOMRAC) is designed to supervise the active and reactive powers of a doubly fed induction generator (DFIG) for wind energy conversion. Simulation results show that the proposed FOMRAC control strategy is more powerful than classical MRAC controls in regards of error, response time and overshoot. Then, including the fractional integral in control law presented a satisfying level of performances. Simulation results illustrate the reliability and robustness of FO-MRAC control towards this change of parameters, where the active and reactive powers follow perfectly the proposed references.

\section{References}

[1] L. Mihet-Popa, F. Blaabjerg, and I. Boldea,"Wind Turbine Generator Modeling and Simulation Where Rotational Speed is the Controlled Variable".EEE transactions on industry applications, vol. 40, no. 1, january/february 2004.

[2] Tapia, A. Tapia and J. R. Séenz, "A new simple and robust control strategy for wind power farm re active power regulation". IEEE 2002.

[3] R. Melício,V.M.F. Mendes, J.P.S. Catalão,"Power converter topologies for wind energy conversion systems: Integrated modeling, control strategy and performance simulation" 2010 Elsevier Ltd. All rights reserved Contents

[4] Shen B, Mwinyiwiwa B, ZhangY, Oo BT. Sensorless Maximum Power Point Tracking of Wind by DFIG Using Rotor Position Phase Lock Loop (PLL). IEEE Transactions on Power Electronics 2009; v. 24 , no. 4.

[5] Cardenas R, Pena R, Proboste J, Asher $G$ and Clare J. MRAS observer for sensorless control of standalone doubly fed induction generators. IEEE Transaction on Energy Convertion 2005; 20: 710-718.

[6] Karimi S, Gaillard A, Poure P, Saadate S. FPGA-Based Real-Time Power Converter Failure Diagnosis for Wind Energy Conversion Systems", IEEE Transactions on Industrial Electronics 2008; v. 55, no. 12.

[7] Anaya-Lara O, Jenkins N, Ekanayake J, Cartwright $P$, Hughes M. Wind energy generation: Modelling and control. Chichester, UK: John Wiley \& Sons, 2009. 
[8] M. Chakib, A. Essadki, T. Nasser, "Robust ADRC Control of a Doubly Fed Induction Generator Based Wind Energy Conversion System", International Conference on Electronic Engineering and Renewable Energy ICEERE 2018

[9] F.E.V. Taveiros, L.S. Barros, F.B. Costa , 'Back-to-back converter state-feedback control of DFIG (doubly-fed induction generator)-based wind turbines, Energy(2015), http://dx.doi.org/10.1016/j.energy2015.06 .027

[10] Oliveira RV, Zamadei JA, Hossi CH. Robust Tuning of the Control Loops of DFIG Wind Turbine Systems. IEEE International Conference on Control Applications (CCA) Part of 2011 IEEE Multi-Conference on Systems and Control Denver, CO, USA. September 28-30, 2011.

[11] M. Kalantar, S.M. Mousavi G « Dynamic behavior of a stand-alone hybrid power generation system of wind turbine, microturbine, solar array and battery storage ", Applied Energy 87 (2010) 3051-3064

[12] Vinagre, B.M., Petras, I., Podlubny, I., Chen, Y.Q.: Using fractional order adjustment rules and fractional order reference models in model-reference adaptive control. Nonlinear Dyn. 29(1-4), 269-279 (2002)

[13] Ladaci, S., Charef, A.: Fractional order model reference adaptive control of a robot arm (in French), Revue Communication Sciences and Technologie, vol. 1, pp. 20-52. ENP Oran, Algeria (2002)

[14] Ladaci, S., Charef, A.: On fractional adaptive control. Nonlinear Dyn. 43(4), 365-378 (2006)

[15] Ladaci, S., Charef, A.: Fractional order adaptive control systems: a survey. In:Mitchell, E.W.,Murray, S.R. (eds.) Classification and Application of Fractals, pp. 261-275. Nova Science Publishers USA (2012)

[16] Hotzel R.,"Contribution à la théorie structurelle de la commande des systèmes linéaires fractionnaires", 1998, Thèse de Doctorat, Université de ParisSud, Centre d'Orsay.

[17] Balaska, S. Ladaci, H. Schulte, A. Djouambi, "Adaptive Cruise Control System for an Electric Vehicle Using a Fractional Order Model Reference Adaptive Strategy", IFAC-PapersOnLine, 52(13) 194-199 (2019).

[18] S.Djebbri, S. Ladaci, A. Metatla and H.Balaska, "Robust MRAC Supervision of a Multi-source Renewable Energy System Using Fractional-Order Integrals", International Conference on Electrical Sciences and Technologies in Maghreb (CISTEM), IEEE, Algeria, 2018.

[19] S. Djebbri , S. Ladaci, A. Metatla, H. Balaska, "Fractional-order model reference adaptive control of a multisource renewable energy system with coupled DC/DC converters power compensation", Energy Systems, 1-41, 2018.

[20] M. Doumi, A. Aissaoui, A. Tahour, M. Abid, "Commande adaptative d'un système éolien ", Rev. Roum. Sci. Techn. - Électrotechn. et Énerg., 60, 1, p. 99-110, Bucarest, 2015.

[21] S. Ladaci, A. Charef, "Fractional order model reference adaptive control of a robot arm (in French)", Revue Communication Sciences \& Technologie. ENP Oran, Algeria. 1: 50-52 (2002).

[22] S. Ladaci, A. Charef, "On Fractional Adaptive Control". Nonlinear Dyn. 43(4): 365-378 (2006)

[23] S. Ladaci,A.Charef, "Fractional order adaptive control systems: A survey". In: Mitchell, E.W., Murray, S.R. (eds.) Classification and Application of Fractals, pp. 261-275. Nova Science Publishers, USA (2012).

[24] S. Djebbri, S. Ladaci, A. Metatla and H.Balaska, "Robust MRAC Supervision of a Multi-source Renewable Energy System Using Fractional-Order Integrals", International Conference on Electrical Sciences and Technologies in Maghreb (CISTEM), IEEE, Algeria, 2018.

[25] S. Zhanfeng, S. Tingna, X. Changliang, C. Wei, "A novel adaptive control scheme for dynamic performance improvement of DFIG-Based wind turbines". Energy 38:104-17, 2012.

[26] K. Ghedamsi,D. Aouzellag, E.M. Berkouk, "Power Control of a Variable Speed Wind Turbine Driving an DFIG". Renevelable energy 33: 2145-2156 (2008).

[27] F.Poitiers,T.Bouaouiche,M.Machmoum," Advanced control of a doubly-fed induction generator for wind energy conversion". Electric Power Systems Research 79: 1085-1096 (2009).

[28] Y.Zhao, Zou, Xu, Kang and J. Chen, "Maximal Power Point Tracking under Speed-Mode Control for Wind Energy Generation System with Doubly Fed Introduction Generator". IEEE 2006.

[29] F.Poitiers, "Etude et commande de generatrices asynchrones pour l'utilisation de l'energie eolienne-machine asynchrone à cage autonome -machine asynchrone à double alimentation reliée au réseau " Thèse de doctorat de l'université de Nantes, le 19 décembre 2003.

[30] Loiseau J.J. et H. Mounier, "Stabilisation de l'équation de la chaleur commandée en flux", ESAIM : Proc., 1998, p. 131144. 